\title{
Photochemistry and photobiology of actinic erythema: defensive and reparative cutaneous mechanisms
}

A.C. Tedesco ${ }^{1}$,

L. Martínez $z^{2}$ and

S. González²

\author{
'Departamento de Química, Faculdade de Filosofia, Ciências e Letras, \\ Universidade de São Paulo, 14040-901 Ribeirão Preto, SP, Brasil \\ ${ }^{2}$ Wellman Laboratories of Photomedicine, Department of Dermatology, \\ Massachusetts General Hospital, Harvard Medical School, Boston, MA 02114, USA
}

\author{
Correspondence \\ A.C. Tedesco \\ Departamento de Química \\ FFCL, USP \\ Av. Bandeirantes, 3900 \\ 14040-901 Ribeirão Preto, SP \\ Brasil \\ Fax: 55 (016) 633-8151 \\ E-mail: atedesco@usp.br \\ Research supported by FAPESP \\ and CNPq.
}

Received November 23, 1995

Accepted March 6, 1997

\begin{abstract}
Sunlight is part of our everyday life and most people accept it as beneficial to our health. With the advance of our knowledge in cutaneous photochemistry, photobiology and photomedicine over the past four decades, the terrestrial solar radiation has become a concern of dermatologists and is considered to be a major damaging environmental factor for our skin. Most photobiological effects (e.g., sunburn, suntanning, local and systemic immunosuppression, photoaging or dermatoheliosis, skin cancer and precancer, etc.) are attributed to ultraviolet radiation (UVR) and more particularly to UVB radiation (290-320 nm). UVA radiation (320-400 nm) also plays an important role in the induction of erythema by the photosensitized generation of reactive oxygen species (singlet oxygen $\left({ }^{1} \mathrm{O}_{2}\right)$, superoxide $\left(\mathrm{O}_{2}{ }^{\circ-}\right)$ and hydroxyl radicals $\left({ }^{\circ} \mathrm{OH}\right)$ ) that damage DNA and cellular membranes, and promote carcinogenesis and the changes associated with photoaging. Therefore, research efforts have been directed at a better photochemical and photobiological understanding of the so-called sunburn reaction, actinic or solar erythema. To survive the insults of actinic damage, the skin appears to have different intrinsic defensive mechanisms, among which antioxidants (enzymatic and non-enzymatic systems) play a pivotal role. In this paper, we will review the basic aspects of the action of UVR on the skin: a) photochemical reactions resulting from photon absorption by endogenous chromophores; b) the lipid peroxidation phenomenon, and c) intrinsic defensive cutaneous mechanisms (antioxidant systems). The last section will cover the inflammatory response including mediator release after cutaneous UVR exposure and adhesion molecule expression.
\end{abstract}

Key words

- Sunburn

- Antioxidant

- DNA photodamage

- Reactive oxygen species

- UV radiation

\section{Introduction}

The sun emits electromagnetic radiation over a wide range of wavelengths that include the ultraviolet $(200-400 \mathrm{~nm})$, visible $(400-760 \mathrm{~nm})$ and the near- and far-infrared regions $(>800 \mathrm{~nm})(1)$. The damage to the ozone layer, an effective barrier against the penetration of ultraviolet radiation to the earth, has had a tremendous impact on interest in the study of the potentially damaging effects of UV light on different organisms, man among them $(2,3)$. Single or multiple exposures to solar radiation without appropriate protection can produce a variety of unwanted effects that are of interest to the 
physician, especially the dermatologist. These effects are the result of acute and chronic photobiological responses that are in turn a consequence of photochemical reactions such as those listed in Table $1(4,5)$.

The basic cutaneous response resulting from exposure to solar radiation is the actinic erythema or "sunburn" which appears 3 to $4 \mathrm{~h}$ after exposure and can last 5 to 6 days depending on the intensity (6). Other signs and symptoms include skin sensitivity to touch, as well as edema, discomfort and pain. Delayed pigmentation or tanning begins after the second or third day and, finally, after a period of 6 to 10 days peeling can occur $(7,8)$.

The photobiological effects of ultraviolet radiation show that the UVB components (290-320 nm) in particular are erythematogenic and carcinogenic, and induce photoaging and direct damage to DNA, RNA, proteins and other cell constituents. Nonetheless, UVA radiation (320-400 $\mathrm{nm}$ ) also plays an important role in the induction of erythema by the photosensitized generation of reactive oxygen species (ROS), such as singlet oxygen $\left({ }^{1} \mathrm{O}_{2}\right)$ or the superoxide $\left(\mathrm{O}_{2}{ }^{\bullet-}\right)$ and hydroxyl radicals $\left({ }^{\circ} \mathrm{OH}\right)$ that damage DNA and cell membranes, and promote carcinogenesis and the changes associated with photo-

Table 1 - Effects of acute and chronic exposure to solar radiation.

Acute exposure
Immediate
Vitamin D synthesis
Immediate darkening reaction
Antidepressant action
Immunosuppressive action
Delayed
Sunburn reaction
Delayed pigmentation
Hyperplastic reaction
Chronic exposure
Photoaging (dermatoheliosis)
Photocarcinogenesis

aging (9). Therefore, both the UVA and UVB components trigger this acute inflammatory response which appears in the form of erythema.

The characteristics associated with the erythema induced by exposure to radiation under laboratory conditions depend on both the intensity and dose of the wavelength used (10-12). UVC (200-290 nm)-induced erythema is the least intense and disappears after a couple of hours, but the erythema induced by UVB and UVA radiation can persist for days since these components penetrate deeper into the skin (13-15). It should be emphasized that even though UVB radiation is more erythematogenic than UVA (the minimal dose required at $297 \mathrm{~nm}$ for the erythema response is 1250 times higher than at $365 \mathrm{~nm})(16,17)$ more photons in the UVA region reach the earth's surface (10-100fold higher for UVA than UVB). Table 2 lists the major reactions induced by the different wavelength ranges of solar radiation.

The histological changes occurring in the skin after exposure also depend on the wavelength of the radiation. These changes may be preceded by the appearance of diskeratotic cells and a reduction in the number of Langerhans cells in the case of UVB exposure (González S, Malallah YH and Johnson B,

Table 2 - Photobiological effects of different parts of the spectra of solar irradiation.

*Heavily pigmented individuals can get immediate pigmentation when exposed to visible light. UVB = Ultraviolet B (290-320 nm); UVA = ultraviolet $A(320-400 \mathrm{~nm})$; visible $=(400-760 \mathrm{~nm}) ; \mathrm{IR}$ $=$ infrared $(760-5000 \mathrm{~nm}) ; \mathrm{IP}=$ immediate pigmentation; $\mathrm{DP}=$ delayed pigmentation (tan).

\begin{tabular}{lllll}
\hline & UVB & UVA & Visible & IR \\
\hline IP & no & yes & no* & no \\
Sunburn & yes & yes & no & no \\
DP & yes & yes & no & no \\
Phototoxicity & yes & yes & yes & no \\
Immunosuppression & yes & yes & no & no \\
Photoaging & yes & yes & yes & no \\
Photocarcinogenesis & yes & yes & no & no
\end{tabular}


unpublished data). For UVA radiation, the histopathological changes are fundamentally restricted to the dermis and depend largely on the presence of photosensitizers (Table $3)$. However, recent studies by Lavker et al. (18) in humans have shown that chronic exposure to UV radiation at sub-erythematogenic doses may also induce the appearance of diskeratotic cells and a reduction in the number of Langerhans cells.

In this review we will focus on erythema as an inflammatory response after exposure to ultraviolet radiation, when the absorption of photons by chromophores in the skin promotes a series of photochemical reactions responsible for this response. First, we will discuss the nature of these reactions, i.e., the production of free radicals and ROS. Several processes will be described, such as lipid peroxidation and its possible role as an initiating mechanism in the photoinduced damage. Also, the antioxidant systems present in the organism as means of protection will be discussed. Finally, we will discuss the biochemical alterations describing the different mediators implicated such as products of arachidonic acid, histamine, cytokines and neuropeptides. These mediators released by keratinocytes and other cutaneous cells, along with the expression of adhesion molecules on their surface, are of fundamental importance for leukocyte adhesion and the onset of the inflammatory response.

\section{Photochemistry of UV-induced erythema: Studies on free radical generation and the production of ROS}

The photoinduced inflammatory response is the result of a series of photochemical reactions taking place after the absorption of non-ionizing radiation by skin chromophores, each of them possessing a different absorption spectrum. At room temperature, most of the molecules are present in their ground state and as a result of absorption of radiation of a given energy (or of a specific wavelength) they undergo an electronic transition to an excited state. The nature of this excited state can be a singlet (if all the electrons have their spins paired) or a triplet (when there is an unpaired electron). Depending on the chromophore and on its environment, the lifetimes of these states can range from picoseconds or nanoseconds (for singlets) to microseconds (for triplets), and these lifetimes can be long enough to permit reactions to occur from these excited states resulting in chemical changes that generate different photoproducts known as free radicals or ROS. It is now well established that both species are continuously produced in vivo. Oxygen radicals can induce a number of disruptive cellular processes, including lipid peroxidation, DNA cleavage, altered enzyme activity, polysaccharide polymerization, and cell

\begin{tabular}{ll} 
Table 3 - Major histological features of ultraviolet radiation-induced erythema. \\
\hline UVB $(290-320 \mathrm{~nm})$ & UVA $(320-400 \mathrm{~nm})$ \\
\hline Epidermal level & Epidermal level \\
- Spongiosis & - Spongiosis \\
- Sunburn cell production & - Sunburn cells \\
- Reduction in Langerhans cell ATPase $(+)$ & Reduction in Langerhans cell density \\
- Vacuolization of melanocytes and keratinocytes & \\
Dermal level & Dermal level \\
- Mast cell degranulation & - Endothelial edema \\
- Slight lymphocytic infiltrate & - Extravascular fibrin depots and erythrocytes \\
& $\bullet$ Infiltrate of round cells with a small \\
& number of neutrophils
\end{tabular}


death. Because the production of radicals is a physiological process, the cells have developed several mechanisms to minimize the effects of these oxyradicals. The organism possesses relatively small molecules ( $\alpha$-tocopherol, $\beta$-carotene, ascorbic acid, etc.) as well as more complex enzymatic systems (superoxide dismutase, catalase, thioredoxin reductase, glutathione peroxidase and reductase) for antioxidant purposes. Most of these UV light-induced cutaneous pathologies will be discussed later in this review.

There is a dose-response relation between the UV-induced erythema and the wavelength of irradiation. Solar radiation of shorter wavelength (UVB region, 290-320 nm) results in both epidermal and dermal changes. However, most UVB is absorbed by chromophores localized mainly in the epidermis, such as nucleic acids, amino acids, urocanic acid and melanin. Many of the chromophores act as protective agents against UV radiation. Melanin is the main chromophore in the epidermis absorbing photons of wavelengths ranging from 350 to $1200 \mathrm{~nm}$.

The degree of the skin response to ultraviolet radiation depends on the localization and distribution of the chromophore as well

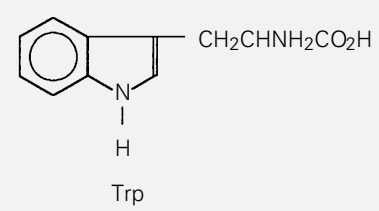

Type I photosensitization

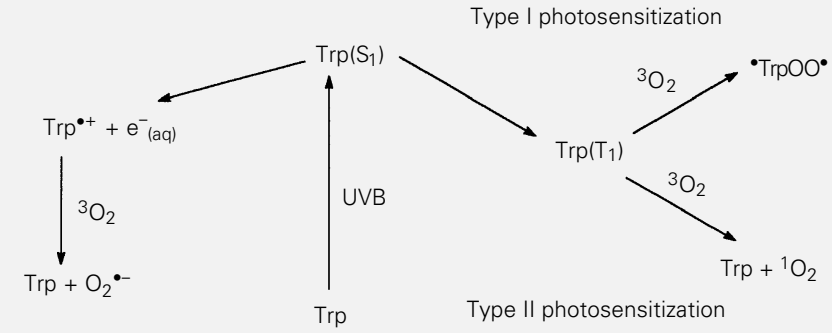

Trp = Tryptophan

$\operatorname{Trp}\left(\mathrm{S}_{1}\right)=$ Singlet state tryptophan

-TrpOO $=$ Trp peroxyl radical form

${ }^{1} \mathrm{O}_{2}=$ Singlet oxygen

$\operatorname{Trp}^{\bullet+}=$ Cationic radical form

$\operatorname{Trp}\left(T_{3}\right)=$ Triplet state tryptophan

$\mathrm{O}_{2}{ }^{--}=$Superoxide anion

${ }^{3} \mathrm{O}_{2}=$ Ground state oxygen

Figure 1 - Photooxidative reaction of tryptophan.

as on skin thickness. Figures 1-5 summarize the photochemical reactions occurring when skin chromophores absorb UV radiation.

Of great photobiological interest $(19,20)$ are the chemical changes of amino acids absorbing ultraviolet radiation. Tyrosine and tryptophan are the most common aromatic amino acids absorbing in the UVB region. At physiological $\mathrm{pH}$, tryptophan (Trp) has an absorption maximum at $290 \mathrm{~nm}$. Upon photon absorption, one of the reactions from the singlet excited stated $\left(\operatorname{Trp}\left(\mathrm{S}_{1}\right)\right)$ involves photoionization and the generation of the tryptophan radical cation $\left(\operatorname{Trp}^{\bullet+}\right)$. The photoejected electron can react with molecular oxygen $\left({ }^{3} \mathrm{O}_{2}\right)$ forming the superoxide radical anion $\left(\mathrm{O}_{2}{ }^{--}\right)$. This reactive oxygen species commonly dismutates to form hydrogen peroxide, $\mathrm{H}_{2} \mathrm{O}_{2}$, and, in the presence of catalytic amounts of copper or iron metalloions (Haber-Weiss/Fenton reactions), can generate the hydroxy radical ${ }^{\circ} \mathrm{OH}$ that can produce damaging effects on biological systems. $\operatorname{Trp}\left(\mathrm{S}_{1}\right)$ can also undergo intersystem crossing to its triplet state $\left(\operatorname{Trp}\left(\mathrm{T}_{1}\right)\right)$ and react with ${ }^{3} \mathrm{O}_{2}$ generating organic peroxyl radicals $\left({ }^{\bullet} \operatorname{TrpOO}{ }^{\bullet}\right)$. $\operatorname{Trp}\left(\mathrm{T}_{1}\right)$ can also generate ${ }^{1} \mathrm{O}_{2}$ through a type $\mathrm{II}$ reaction (i.e., energy transfer, see Figure 1).

It is commonly accepted that even if tyrosine (Tyr) absorbs radiation in the UV region it ultimately transfers the absorbed energy to tryptophan residues in proteins (20). In vitro studies have demonstrated that the 254 run photolysis of Tyr yields dopamine as one of the main photoproducts (21). After a complex series of reactions, polymerization to melanin occurs (Figure 2).

The nitrogen bases are the main chromophores in nucleic acids capable of absorbing ultraviolet radiation in the 250-270 $\mathrm{nm}$ range. Photochemical alterations in nucleic acids have a major impact at the cellular level, leading to cell death, mutagenesis and photocarcinogenesis.

A variety of photoproducts have been identified (22-25), with the cyclobutyldimers 
and photohydrates of the pyrimidine bases being formed at higher levels (Figure 3 ). The formation and yields of these products vary both with the nature of the base and the sequence in the nucleic acid strand. Cyclobutyldimers between adjacent thymines are produced at higher yields than any other pyrimidine combination and so are the cytosine photohydrates. Another product involving covalent coupling of two pyrimidine bases is the pyrimidine-(6-4)-pyrimidone photoadduct, formed in greater yields in thymine-cytosine sequences. Early observations have demonstrated that purine nucleic acid components and particularly guanine, as the free base or the related nucleoside and nucleotides, are more readly photooxidized by a variety of photosensitizers than are their pyrimidine analogs. Figure 5 shows the guanine radical intermediates from type I photoreactions and from the ${ }^{\bullet} \mathrm{OH}$ reaction giving rise to identical decomposition products. Guanine can also be attacked by singlet oxygen in a type II photoreaction. These radical intermediates can be employed as a diagnostic tool for the assessment of photo-oxidative damage to DNA.

The cell possesses specific enzymes capable of repairing some of these photoproducts (i.e., endonucleases) and loss of activity of these enzymatic systems (i.e., xeroderma pigmentosum) increases the likelihood that damage will persist in the genetic material after UV exposure.

Urocanic acid (UA), a deaminated histidine, is the main chromophore absorbing $\mathrm{UV}$ radiation in the stratum corneum. It is produced by the action of the enzyme histidase on the amino acid histidine. The absence of urocanase in the epidermis prevents the transformation of UA into the imidazolone propionic acid. Several investigators (26-28) have suggested that UA is a natural sun block since its absorption spectrum covers the region from 240-300 nm (maximum at $275 \mathrm{~nm}$ ) overlapping the main erythematogenic region (i.e., 290-310 nm). The

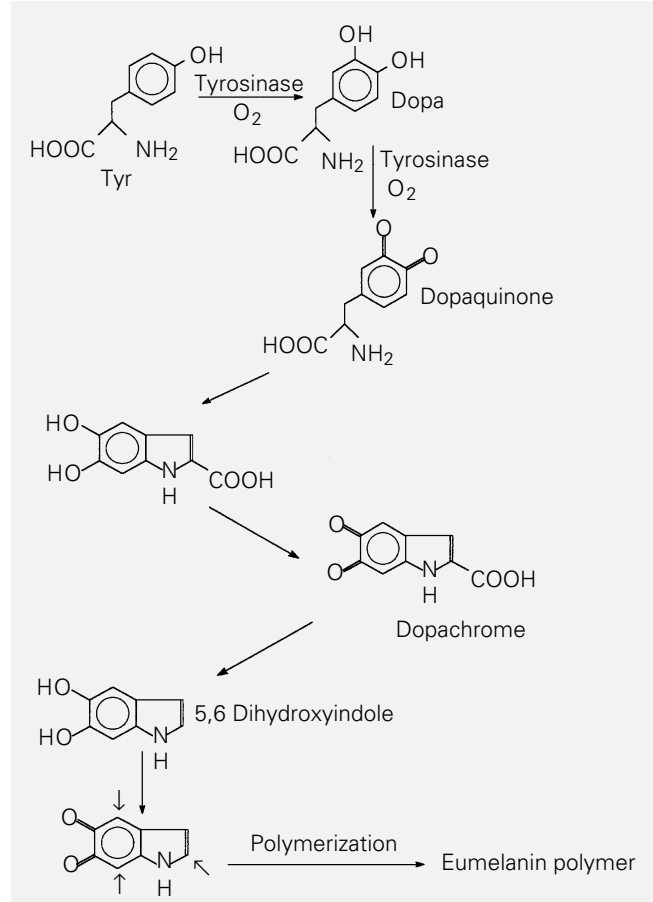

Figure 2 - Photooxidation of tyrosine. Melanin polymerization (small arrows, sites of polymerization). trans-isomer of UA is naturally present in the skin and after absorption of photons undergoes photoisomerization to the cis-isomer (Figure 4) which mimics several of the immunomodulatory effects of UV radiation.

The majority of the reactive species generated by the action of UV radiation on skin chromophores are radicals. Free radicals are, by definition, chemically active species which possess an unpaired electron in their orbitals. Biological systems are usually exposed to different types of radicals generated either endogenously or as a result of some exogenous injury. Radicals can undergo addition or electron-transfer reactions with different cellular components and have thus been implicated in the ethiopathogenesis of several diseases.

Free radicals can be neutral or charged species. An example of a neutral radical is the thyoil radical $\left(\mathrm{RS}^{\bullet}\right)$ that can be produced by direct $\mathrm{H}$-atom abstraction from a thiol group by another organic radical. This radical can be generated by the activation of thioredoxin reductase, an enzymatic antioxi- 
dant system (29). This epidermal membraneassociated free radical scavenging system that catalyzes the reduction of oxygen radicals to peroxide, although widely distributed
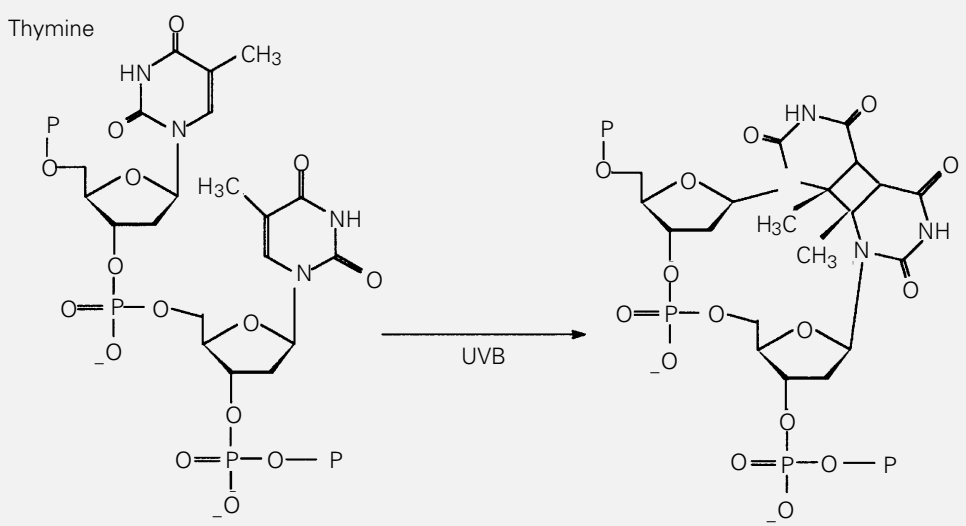

Cyclobutyl-pyrimidine dimer
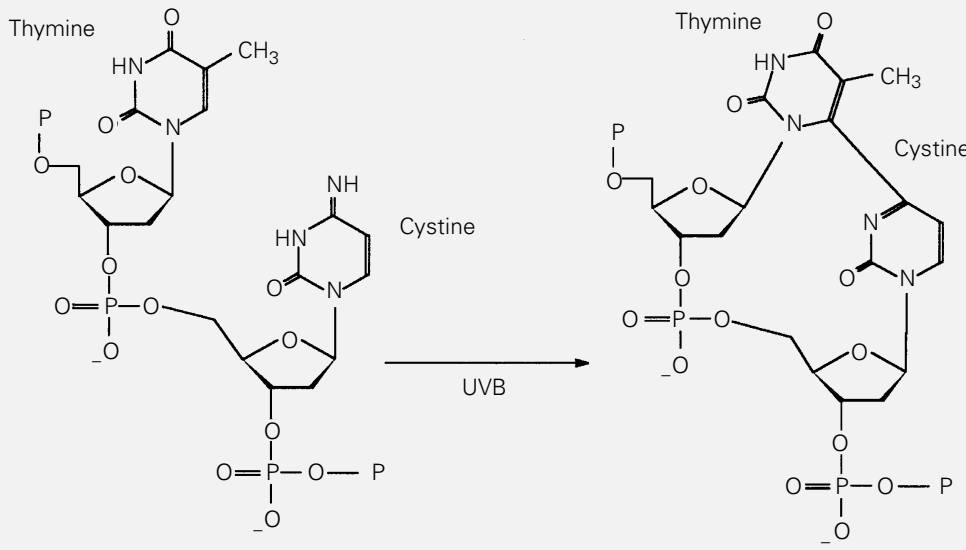

(6-4) Photoadducts

Figure 3 - Photosensitized dimerization of nucleic acids.

Figure 4 - Photoisomerization of urocanic acid.

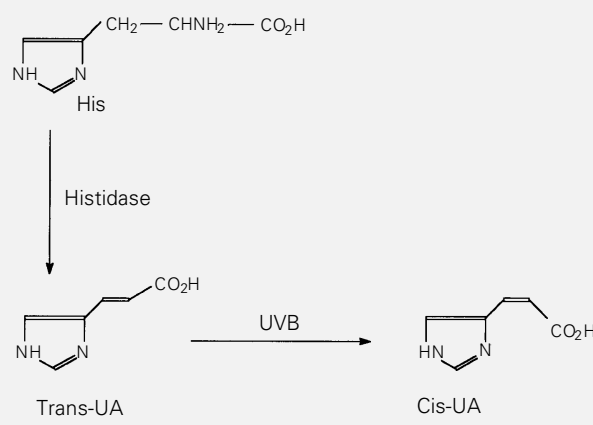

in a variety of organisms and tissues, and located preferentially on the outer membrane surface in human epidermis, may be the first line of defense against free radical production induced by UV. The thioredoxin reductase/ thioredoxin system has been implicated in a number of other antioxidant reactions (29).

Pyridinyl radicals are radical cations (i.e., positively charged radicals) which are involved in the formation of the chemical structure of two important coenzymes, $\mathrm{NAD}^{+}$and $\mathrm{NADP}^{+}$(30). The best known negatively charged radical is the oxyradical $\mathrm{O}_{2}{ }^{\circ-}$. The superoxide radical anion can be generated by different compounds and physical agents, such as ionizing radiation, ultraviolet radiation, hyperbaric oxygen and photosensitizing agents $(31,32)$.

Although most of the oxygen consumed during cellular respiration is reduced to water by cytochrome $\mathrm{C}$ oxidase (33), a small amount of oxygen undergoes sequential stepwise univalent reduction and this is enough to produce a sufficient quantity of the superoxide radical and, ultimately, different ROS. These reactive species affect a variety of biological processes by damaging cellular membranes, enzymes, lipids, nucleic acids, and mitochondria by affecting the electron-transport chain. Among many processes that contribute to the generation of ROS are 1) the autooxidation of metabolites such as hydroquinones, thiols, hemoglobin (34), and catecholamines (33); 2) the enzymatic oxidation mediated by xanthine oxidase (35), aldehyde oxidase and orto-hydrodehydrogenase (31), and 3) the autooxidation of reduced species of the electron-transport chain generated from organelles such as mitochondria, microsomes or nuclei (36-38).

Oxidative stress may be regarded as an imbalance between the production of free radicals and their defense mechanisms. Such inefficiency of defense mechanisms may be due either to their relative deficit or inaccessibility or to their exhaustion following excess free radical production. Oxidative stress 
can be prevented or repaired by interventions that antagonize metabolic pathways of free radical generation, or that emulate or amplify physiological defense mechanisms. This toxic effect generated by hyperoxia or the inappropriate metabolism of oxygen is a well-defined cause of toxicity in biological systems. Most of the ROS generated after exposure of the skin to solar radiation (3941) have a relatively short lifetime. Cellular injury caused by ROS involves generation of superoxide anion and hydrogen peroxide, but the most reactive mediator of such damage, however, appears to be the hydroxyl radical. Hydrogen peroxide is produced directly by a variety of oxidases and is also produced by dismutation of the superoxide anion (42-44).

$$
2 \mathrm{O}_{2}{ }^{\bullet-}+2 \mathrm{H}^{+} \rightarrow \mathrm{H}_{2} \mathrm{O}_{2}+\mathrm{O}_{2}
$$

This molecule must be considered dangerous because its small size and lack of charge allow it to diffuse across biological membranes and then, by reduction of $\mathrm{H}_{2} \mathrm{O}_{2}$ mediated by catalytic amounts of metal cations such as iron or copper in a reaction called iron-catalyzed Haber-Weiss reaction or sometimes Fenton reaction, produces $\mathrm{OH}^{-}$ and ${ }^{\bullet} \mathrm{OH}(32,43,45)$. The relevant reactions are:

$$
\begin{gathered}
\mathrm{Fe}^{3+}+\mathrm{O}_{2}^{\bullet-} \rightarrow \mathrm{Fe}^{2+}+\mathrm{O}_{2} \\
\mathrm{Fe}^{2+}+\mathrm{H}_{2} \mathrm{O}_{2} \rightarrow \mathrm{Fe}^{3+}+\mathrm{OH}^{-}+{ }^{\bullet} \mathrm{OH} \\
\mathrm{O}_{2}^{\bullet-}+\mathrm{H}_{2} \mathrm{O}_{2} \rightarrow \mathrm{OH}^{-}+\cdot \mathrm{OH}+\mathrm{O}_{2} \\
\mathrm{Fe}^{3+}
\end{gathered}
$$

Another reactive oxygen species formed from molecular oxygen is ${ }^{1} \mathrm{O}_{2}$. In biological systems, ${ }^{1} \mathrm{O}_{2}$ is generated by absorption of incident light of specific wavelengths by excitable endogenous or exogenous molecules known as photosensitizers. This type of photosensitization is known as type II $(46,47)$. A large number of sensitizers occur naturally in organisms (riboflavin, 4thiouridine and 2-thiouracil, bilirubin, etc.), but many others need to be added exog- enously to the system. The energy of the triplet excited state for the sensitizers is then transferred to an adjacent triplet (unexcited) oxygen molecule, raising molecular oxygen to the singlet oxygen. There are two excited states of ${ }^{1} \mathrm{O}_{2}$ of 23 and $37 \mathrm{kcal}$, the latter having the shorter lifetime. Even if the energy of the photons in the ultraviolet and visible regions is enough to generate singlet oxygen, $\mathrm{O}_{2}$ does not absorb at these wavelengths; therefore, ${ }^{1} \mathrm{O}_{2}$ can only be generated, as established before, by an energytransfer mechanism involving $\mathrm{O}_{2}$. This mechanism constitutes the underlying principle of photodynamic therapy (PDT). In PDT, an exogenous chromophore (i.e., usually a photosensitizing dye) is taken up by the cell and irradiated with light of a specific wavelength usually corresponding to the wavelength of maximum absorption of the dye $(48,49)$. The excited sensitizer transfers the absorbed energy to $\mathrm{O}_{2}$, generating ${ }^{1} \mathrm{O}_{2}$ and returning to its ground electronic state. ${ }^{1} \mathrm{O}_{2}$ then reacts with different molecules through a series of complex biochemical reactions in different cellular components (DNA, membrane lipids, proteins, etc.), triggering the destruction and necrosis of neoplastic tissue.

Enzyme generation of ${ }^{1} \mathrm{O}_{2}$ has been detected by IR spectroscopy and luminescence emission at $1268 \mathrm{~nm}$ from enzyme systems such as chloroperoxidase- $\mathrm{H}_{2} \mathrm{O}_{2}-\mathrm{Cl}^{-}$, lacto-

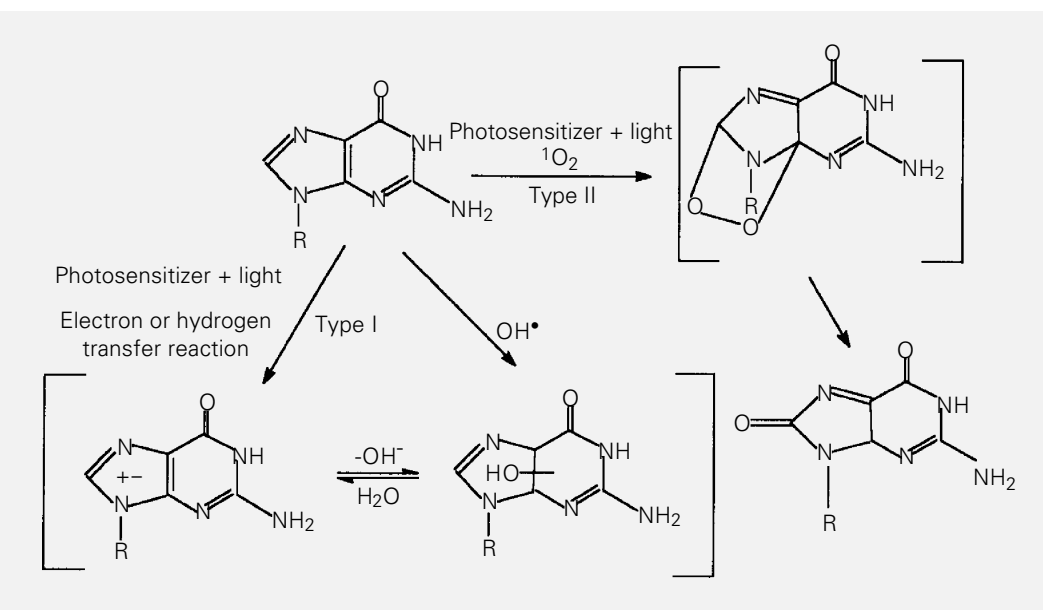

Figure 5 - Guanine radical intermediates from type I and type II photosensitization. 
peroxidase- $\mathrm{H}_{2} \mathrm{O}_{2}-\mathrm{Br}^{-}$, and cyclooxygenase (50-55). This was the first direct experimental confirmation of ${ }^{1} \mathrm{O}_{2}$ being produced as a chemical reactant generated by dark enzymatic systems, although this possibility has been critically discussed in the literature $(56,57)$. As noted by Kanofsky (51), this biochemical production of ${ }^{1} \mathrm{O}_{2}$ "should not be uncritically extrapolated to living systems".

\section{Lipid peroxidation: initiating event in photooxidative stress}

We have already discussed the different ROS generated after exposure of the skin to solar UV radiation (39-41) which have relatively short lifetimes. Biological membranes that are rich in polyunsaturated fatty acids (PUFA) (58) are vulnerable targets for free radical attack, especially by hydroxyl radicals produced in the Fenton reaction.

The hydroxyl radical reacts with methylene groups of unsaturated lipids by $\mathrm{H}$-atom abstraction producing a lipid radical $\left(\mathrm{L}^{\bullet}\right)$ which in a reaction with $\mathrm{O}_{2}$ forms the lipid peroxyl radical (LOO`). This $\mathrm{LOO}^{\bullet}$ radical can react with another methylene group of another unsaturated fatty acid generating a lipid peroxide $(\mathrm{LOOH})$ and another $\mathrm{L}^{\bullet}$ which in the presence of metal ions forms alkoxy $\left(\mathrm{LO}^{\circ}\right)$ and peroxyl radicals.

Lipid peroxide generated by oxidative stress of UV light in the skin $(58,59)$ has been known to be potentially deleterious for cellular function, having cytotoxic effects, stimulatory or inhibitory effects on enzymes, and cell membrane damage and carcinogenic effects. Recent observations (60) indicate that the serum levels of lipid peroxide after cutaneous exposure to UVB radiation reach a maximum $18 \mathrm{~h}$ later, decreasing during the next 2 or 3 days.

Black and associates (61) have emphasized the observation that irradiation of the skin both in vitro and in vivo leads to the photooxidation of sterols. One of the photo- products isolated is cholesterol- $\alpha$-oxide (weakly carcinogenic), leading to the speculation that in vivo photooxidation might be the route for photocarcinogenesis.

Thus, lipid peroxidation affects a variety of cellular functions and may precede or be concurrent with other mechanisms leading to damage to the genetic material and cellular proteins.

It appears that lipid peroxide attached to the skin causes various kinds of cell damage, and leads to skin disease and skin tumors. Lipid peroxidation is considered at present to be one of the basic mechanisms involved in reversible and irreversible cell and tissue damage.

We will devote another section to the interaction of these lipid peroxides with other mediators derived from the uncontrolled oxidation of arachidonic acid and eicosapentanoic acid as part of the biochemical alterations inducing the inflammatory response.

\section{Antioxidant systems and photooxidative stress}

The skin is the major organ exposed to external radiation and thus is potentially affected by the action of free radicals and other ROS. Fortunately, different systems dealing with oxidative stress have evolved to maintain cellular integrity (32). In these elaborate systems, biologic antioxidants play a pivotal role. Even with these defense mechanisms, the requirements for the protection of the skin can be exceeded after considerable solar exposure. Actinic erythema is produced when the consumption of the antioxidants exceeds their regeneration, thereby affecting cellular functions.

Protection of the skin against these free radicals and reactive oxygen species can be achieved by 1) trapping the initial pro-oxidizing species, 2) sequestering heavy metals, preventing the initiating and propagating steps for the reactions producing free radi- 
cals, 3) trapping the secondary radicals that can propagate the chain reaction or reduce oxidized groups, and 4) repair of macromolecules and cell renovation.

The antioxidant systems that prevent free radical chain propagation by interrupting the initiation can be categorized as enzymatic systems, including superoxide dismutase (31), catalase (62), thioredoxin reductase (29), and several isoenzymes of glutathione peroxidase and glutathione reductase, the latter functioning to restore the levels of reduced glutathione. These enzymatic antioxidants mainly serve an intracellular function against oxidative stress, being absent or present in small amounts in the extracellular spaces. The organism also has a group of low molecular weight antioxidants which can be divided into lipid- and water-soluble molecules. $\beta$-Carotene, a precursor of vitamin $A$, and $\alpha$-tocopherol (vitamin E) are the main lipid-soluble non-enzymatic antioxidants and are mainly confined to cell membranes and low-density lipoprotein. Among water-soluble antioxidants, ascorbate is the most efficient antioxidant. Table 4 summarizes the most important characteristics of these systems.

Experimentally, the topical application of antioxidants has shown promising results in preventing damage and the photoinduced inflammatory response (63-66). Although melanin absorbs photons in the far UV and visible regions of the solar spectrum acting as a natural filter (67), it can also trap some of these reactive species and function as an antioxidant (40).

\section{Biochemical alterations in the photoinduced erythema}

The skin chromophores initiating the photochemical reaction that leads to the inflammatory response are unknown, but the outcome of these reactions results in erythema, edema, burning sensation and pain. Acute exposure of the skin to ultraviolet radiation induces the synthesis and liberation of eicosanoids (products derived from arachidonic acid), histamine, kinins, cytokines and other chemotactic factors (7), as well as the expression of adhesion molecules on the surface of epidermal and dermal cells. All these mediators activate endothelial cells in the dermis, increase vascular permeability and promote the accumulation of inflammatory cells 12 to $14 \mathrm{~h}$ after the injury. Natajaran (68) has recently noted that the effect of oxidants (ROS) on signal transduction in vascular endothelium is directly related to the pathogenesis of the inflammatory response. We will now turn to the discussion of the biochemical alterations that mediate the photoinduced erythema and the implication of the adhesion molecules relevant to the pathogenesis of the inflammatory response.

\section{Biochemical mediators in the pathogenesis of erythema}

\section{Prostaglandins and other products derived from arachidonic acid}

The eicosanoids are derived from arachidonic acid after activation of a phospholipase (69-71) and play an important role as mediators of the inflammatory response (72). The activation of this phospholipase is induced by lipid peroxidation (73). In vitro studies have demonstrated the activation of phospholipase $\mathrm{A}_{2}$ and lysophospholipase $(74,75)$ after UVB irradiation. The activation of phospholipases $A_{2}$ and $C$ (76) has been suggested to occur before the increase in the synthesis of phosphorylcholine and eicosanoids after UVA irradiation. Both the nature of the eicosanoids and the levels they reach depend on the wavelength of the radiation $(73,74)$. For example, cyclooxygenase inhibitors administered during the first $24 \mathrm{~h}$ after UVB exposure reduced by about $50 \%$ the severity of photoinduced erythema (7780). However, indomethacin administered 
Table 4 - Systemic antioxidant enzymes.

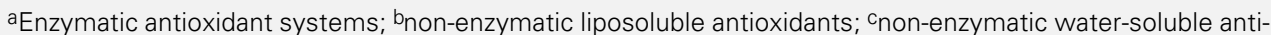
oxidants.

\begin{tabular}{|c|c|c|}
\hline Catalase $^{a}$ & Heme group & $\begin{array}{l}\text { - Catalyzes the dismutation of hydrogen } \\
\text { peroxide } \\
\text { - Localized at the cutaneous, hepatic and } \\
\text { hematic levels (62) }\end{array}$ \\
\hline Thioredoxin reductase ${ }^{a}$ & Membrane associated & $\begin{array}{l}\text { - Localized on the superficial external cell } \\
\text { membrane, it acts as the first form of } \\
\text { epidermal defense } \\
\text { - Catalyzes the reduction of oxygen } \\
\text { radicals to peroxide ions } \\
\text { - Found in keratinocytes, Langerhans cells, } \\
\text { and melanocytes (29) }\end{array}$ \\
\hline $\begin{array}{l}\text { Superoxide dismutase } \\
(\text { SOD) }\end{array}$ & Metalloprotein family & $\begin{array}{l}\text { - Catalyzes the removal of superoxide } \\
\text { anion }\left(\mathrm{O}_{2}^{\bullet-}\right) \\
\text {-SOD forms: } \mathrm{Cu}^{2+-} \mathrm{Zn}^{2+} \mathrm{SOD} \text { in cytosol, } \\
\mathrm{Mn}^{3+} \mathrm{SOD} \text { in mitochondrial matrix } \\
\text { - Extracellular form linked to the cell } \\
\text { surface and heparin sulfate, controlling } \\
\text { the release of superoxide anion }\end{array}$ \\
\hline Glutathione peroxidase ${ }^{a}$ & $\begin{array}{l}\text { Soluble form } \\
\text { (selenium enzymes) } \\
\text { Membrane-associated form }\end{array}$ & $\begin{array}{l}\text { - Reduces } \mathrm{H}_{2} \mathrm{O}_{2} \text {, producing alkyl- } \\
\text { hydroperoxide } \\
\text { - Reduces phospholipid hydroperoxide }\end{array}$ \\
\hline
\end{tabular}

$\alpha-$ Tocopherolb

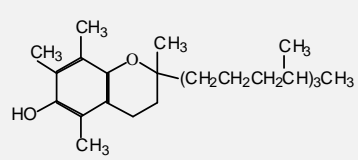

- Acts at the membrane level, intercepting free radicals and ROS, as well as reactive intermediate lipids

- After oxidative reaction produces tocopherol radical, which is reduced by ascorbate

Ubiquinone $^{b}$

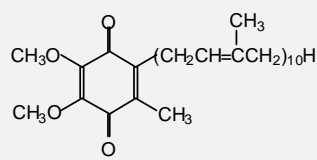

- Participates in transmembrane transport of protons and electrons

Vitamin $\mathrm{C}^{\mathrm{C}}$

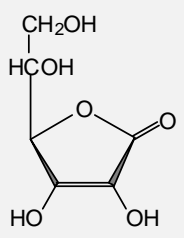

- Reacts directly with reactive oxygen species

-Destroys hydrogen peroxide

Glutathione (reduced) ${ }^{\mathrm{c}}$

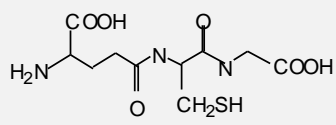

-Acts as an enzymatic factor and as an enzyme cofactor in eicosanoid synthesis

- Regeneration of vitamin C

- Reduces ultraviolet B cytotoxic effects

-Traps ${ }^{1} \mathrm{O}_{2}$ and peroxy radicals 
either topically or intradermally has no effect on erythema when the latter is induced only by UVA radiation (81).

Regarding the kinetics of the increase in their concentration, there is a fast release of prostaglandins (PG) $\mathrm{E}_{2}, \mathrm{~F}_{2}, \mathrm{D}_{2}$ and 12-RHETE, even before the erythema has become clinically perceptible, and they persist for $48 \mathrm{~h}$ reaching a maximum level 18-24 $\mathrm{h}$ after exposure to UVB $(14,73,77,82)$. In $v i$ tro studies have confirmed the dose-dependent increase in the levels of the released eicosanoids (65). Prostacyclin levels increase 5-9 $\mathrm{h}$ after irradiation and return to basal levels after $24-48 \mathrm{~h}(8,83)$. These results follow a similar pattern compared with the release of eicosanoids from keratinocytes and mast cells, supporting their role in the pathogenesis of UVB-induced erythema (84). The increase in $\mathrm{PG} \mathrm{E}_{2}, \mathrm{D}_{2}$ and prostacyclin after UVA irradiation is also dose-dependent and reaches maximum levels 5-9 $\mathrm{h}$ after exposure. After $15 \mathrm{~h}$, these substances begin to decrease and finally return to basal levels $24 \mathrm{~h}$ later (8). $\mathrm{PG} \mathrm{E}_{2}$ seems to be involved in the epidermal growth resulting from the exposure and increased vascular permeability (85) through the increase in leukotriene $\mathrm{C} 4$ levels. Nonetheless, leukotriene B4 also plays an important role in the chemotaxis of inflammatory cells $(72,86)$.

\section{Histamine}

This mediator plays a very important role in the development of erythema $(14,83,87$, 88). In vivo studies in humans have shown that mast cell degranulation occurs $4 \mathrm{~h}$ after skin irradiation $(14,89)$, with histamine reaching maximal levels 9 to $15 \mathrm{~h}$ later and returning to basal levels after $24 \mathrm{~h} \mathrm{(8)}$. Some authors (90-92) have shown that isolated mast cells can be stimulated to release histamine. This histamine release is of a noncytotoxic nature at low peroxidase concentrations, and the cells undergo cytotoxic reactions only at high peroxidase concentrations.
It has also been shown (91) that $\mathrm{H}_{2} \mathrm{O}_{2}$ added exogenously or generated by the xanthine oxidase system activates mast cells for noncytotoxic histamine release. The agents released or generated from ROS during skin irradiation may act as degranulating or lytic substances on mast cells (91).

\section{Neuropeptides}

In vitro studies have shown that suninduced inflammation may also be the result of primary stimuli of mediators other than histamine, including tachykinins and other families closely related to neuropeptides (93). In this regard, recognition of the similarity between sunburn pain and causalgia has suggested a new pathogenic approach implicating depletion of neuropeptides such as substance P (94).

\section{Cytokines}

Ultraviolet radiation promotes the release of pro-inflammatory cytokines from keratinocytes and other cells in the skin (e.g., interleukin (IL)-1, IL-3, IL-6, IL-8, IL-10, tumor necrosis factor (TNF)- $\alpha$, transforming growth factor (TGF)- $\beta$, GM-CSF, etc.) (95-98). All of these mediators seem to contribute to the formation of a special microenvironment for Langerhans cells and, subsequently, local UV-induced immunosuppression. In this regard, urocanic acid isomerization has been shown to induce TNF- $\alpha$ release and it has even been suggested that this mediator may be related to IL-10 (99). Furthermore, some of these cytokines (IL-1, IL-8) are also involved in the recruitment phase of the UVinduced inflammatory response due to their chemotactic activity $(98,100)$, the former with a direct in vitro parallelism with $\mathrm{PG} \mathrm{E}_{2}$ levels, suggesting a possible connection between them (101).

Finally, in vivo and in vitro studies have implicated IL-1 $(102,103)$ and IL-6 (104) in the general symptoms of the acute phase 
following excessive solar exposure, such as fever and leukocytosis.

\section{Expression of adhesion molecules in UV-induced cutaneous inflammation}

The intercellular adhesion molecules (ICAM-1), endothelial adhesion molecules (E-selection or ELAM-1) and vascular adhesion molecules (VCAM-1) are regulated by cytokines, among other mediators, and implicated in the phenomenon of leukocyte adhesion (105). These cellular adhesion glycoproteins mediate the interaction between cells in the epidermis and dermis and those that are present in the infiltrate after diffusing from vascular walls (106). Therefore, these molecules seem to be crucial in the formation of the inflammatory infiltrate of actinic erythema.

Under normal conditions, ELAM-1 and VCAM-1 are minimally expressed but are induced by IL-1 and TNF (107). In vitro studies have shown their relationship with polymorphonuclear antibodies and monocytes but not with lymphocytes $(108,109)$. Recently, Norris and coworkers (110) demonstrated that UVB radiation is an efficient stimulus for the expression of ELAM-1, reaching maximum levels $24 \mathrm{~h}$ after irradiation. Two mechanisms have been proposed for their induction: a) a direct stimulation of endothelial cells after absorption of photons in the UV region, or b) an indirect pathway mediated by IL-1 released from keratinocytes after the injury. Some similarities have been observed between the kinetics for the expression of ELAM-1 and the accumulation of inflammatory cells, showing that these surface molecules play an important role in the adhesion process for inflammatory cells.

Regarding other molecules involved in this inflammatory response, it has been observed that ultraviolet radiation can modulate the expression of ICAM-1 previously induced by the cytokines IL- 1 and TNF $(111,112)$. Cornelius and collaborators $(113)$ have recently shown that UVB radiation directly upregulates the expression of ICAM-1 independently of IL-1 and TNF, a selectivity that has not been observed in the expression of ELAM-1 and VCAM-1.

In conclusion, it is conceivable that several manifestations of these reactions are induced by a direct action of photons on DNA and other chromophores and by generation of free radicals and other reactive oxygen species. Additionally, generation of prostaglandins, leukotrienes, histamine, cytokines and other mediators, as well as the expression of adhesion molecules may be involved in the inflammatory response. However, ongoing research exploring other mechanisms will ideally further our biochemical and biological understanding of actinic erythema.

\section{References}

1. Kochevar IE, Pathak MA \& Parrish JA (1987). Photophysics, photochemistry and photobiology. In: Fitzpatrick TB, Eisen AZ, Wolff K, Freedberg IM \& Austen KF (Editors), Dermatology in General Medicine. McGraw-Hill, New York, 1441-1451.

2. Coohill TP (1991). Action spectra again? Photochemistry and Photobiology, 54: 859-870.

3. González S \& Joshi PC (1994). Stratospheric ozone depletion. Its relevance in the biological systems. Implication in the development and promotion of skin cancer. Dermocosmética Clínica, 2: 169-175.
4. Setlow RB, Grist E, Thompson K \& Woodhead AD (1993). Wavelengths effective in induction of malignant melanoma. Proceedings of the National Academy of Sciences, USA, 90: 6666-6670.

5. Sober AJ (1987). Solar exposure in the etiology of cutaneous melanoma. Photodermatology, 4: 23-31.

6. Kligman LH \& Kligman AM (1986). The nature of photoaging: Its prevention and repair. Photodermatology, 3: 215-217.

7. Soter NA (1990). Acute effects of ultraviolet radiation on the skin. Seminars in Dermatology, 9: 11-15.
8. Hawk JLM, Black AK, Jaenicke KF, Barr RM, Soter NA, Mallett Al, Gilchrest BA, Hensby CN, Parrish JA \& Greaves MW (1983). Increased concentrations of arachidonic acid, prostaglandins $E_{2}, D_{2}$ and 6 -oxo- $F_{1 \alpha}$, and histamine in human skin following UVA irradiation. Journal of Investigative Dermatology, 80: 496-499. 
9. Pathak MA \& Carraro C (1988). Reactive oxygen species in cutaneous photosensitivity reactions in porphyrias, PUVA photochemotherapy, and melanin pigmentation. In: Hayaishi O, Imamura S \& Myachi Y (Editors), The Biological Role of Reactive Oxygen Species in the Skin. Tokyo University Press, Tokyo, 75-84.

10. Bachem A (1955). Time factors of erythema and pigmentation, produced by ultraviolet rays of different wavelengths. Journal of Investigative Dermatology, 25: 215-218.

11. Gange RW (1987). Acute effects of ultraviolet radiation on the skin. In: Fitzpatrick TB, Eisen AZ, Wolff K, Freedberg IM \& Austen KF (Editors), Dermatology in General Medicine. McGraw-Hill, New York, 1451-1457.

12. Cavallo J \& DeLeo VAS (1986). Sunburn. In: DeLeo VAS (Editor), Dermatology Clinics: Photosensitivity Diseases. WB Saunders, Philadelphia, 181-187.

13. Harber LC \& Bickers DR (1989). Photosensitivity Diseases. WB Saunders, Philadelphia, 128.

14. Gilchrest BA, Soter NA, Stoff JS \& Mihm MC (1981). The human sunburn reaction: histological and biochemical studies. Journal of the American Academy of Dermatology, 5: 411-422.

15. Gilchrest BA, Soter NA, Hawk JLM, Barr RM, Black AK, Hensby CN, Mallet Al, Greaves MW \& Parrish JA (1983). Histologic changes associated with ultraviolet A-induced erythema in normal human skin. Journal of the American Academy of Dermatology, 9: 213-219.

16. Parrish JA, Jaenicke KF \& Anderson RR (1982). Erythema and melanogenesis action spectra of normal human skin. Photochemistry and Photobiology, 36: 187-191.

17. Kollias N, Malallah YH, Al-Almi H, Bager A \& González S (1996). Erythema and melanogenesis action spectra for skin type V. Journal of Investigative Dermatology (in press).

18. Lavker RM, Gerverick GF, Veres D, Irwin CJ \& Haidbey KH (1995). Cumulative effects from repeated exposures to suberythemal doses of UVB and UVA in human skin. Journal of the American Academy of Dermatology, 32: 53-62.

19. Cree D (1984). Photophysics and photochemistry of near-UV absorbing amino acids. I. L-tryptophan and its simple derivatives. Photochemistry and Photobiology, 39: 537-562.
20. Cree D (1984). Photophysics and photochemistry of near-UV absorbing amino acids. Il. Tyrosine and its simple derivatives. Photochemistry and Photobiology, 39: 563-575.

21. McLaren AD \& Shugar D (1964). Photochemistry of Proteins and Nucleic Acids. Macmillan, New York.

22. Cadet J \& Vigny P (1990). The photochemistry of nucleic acids. In: Morrison $\mathrm{H}$ (Editor), Bioorganic Photochemistry. John Wiley \& Sons, New York, 3-272.

23. Cadet $J$ \& Weinfeld M (1993). Detecting DNA damage. Analytical Chemistry, 65: 675A-682A.

24. Cadet J, Anselmino C, Douki T \& Voituriez $L$ (1992). Photochemistry of nucleic acids in cells. Journal of Photochemistry and Photobiology B: Biology, 15: 277-298.

25. Douki T \& Cadet J (1995). UV and nucleic acids. EXS, 73: 173-197.

26. Baden HP \& Pathak MA (1967). The metabolism and function of urocanic acid in skin. Journal of Investigative Dermatology, 48: 11-17.

27. Morrison H, Avnir D \& Fagan BG (1980). Z/E photoisomerization of urocanic acid. Photochemistry and Photobiology, 32 711-714.

28. Morrison H \& Pandey BG (1983). Urocanic acid photobiology. Photoaddition of $\mathrm{N}, \mathrm{N}$-dimethylthymine to urocanic acid. Photochemistry and Photobiology, 38: 2327.

29. Schallreuter KU \& Wood JM (1986). The role of thioredoxin reductase in the reduction of free radicals at the surface of the epidermis. Biochemical and Biophysical Research Communications, 136: 630-637.

30. Kosower EM (1976). Pyridinyl radicals in biology. In: Pryor WA (Editor), Free Radical in Biology. Academic Press Inc., New York, 1-53.

31. Fridovich I (1978). The biology of oxygen radicals. Science, 201: 875-880.

32. Darr D \& Fridovich I (1994). Free radical in cutaneous biology. Journal of Investigative Dermatology, 102: 671-675.

33. Antonini E, Brunori M, Greenwood C \& Malmtrom BG (1970). Catalytic mechanism of cytochrome oxidase. Nature, 228: 936.

34. Misra HP \& Fridovich I (1971). The generation of superoxide radical during the autooxidation of hemoglobin. Journal of Biological Chemistry, 247: 6960-6962.

35. McCord JM \& Fridovich I (1968). The reduction of cytochrome C milk xanthine oxidase. Journal of Biological Chemistry, 243: 5753-5760.
36. Loschem G, Azzi A, Richler C \& Flohe L (1974). Superoxide radicals as precursors of mitochondrial hydrogen peroxide. FEBS Letters, 42: 68-72.

37. Turrens J \& Boveri A (1980). Generation of superoxide anion by NADH dehydrogenase of bovine heart mitochondria. Journal of Biochemistry, 191: 421-427.

38. Boveri A (1977). Mitochondrial production of superoxide radical and hydrogen peroxide. Advances in Experimental Medicine and Biology, 78: 67-82.

39. Norins AL (1962). Free radical formation in the skin following exposure to ultraviolet light. Journal of Investigative Dermatology, 39: 445-448.

40. Pathak MA \& Stratton K (1968). Free radicals in human skin before and after exposure to light. Archives of Biochemistry and Biophysics, 123: 468-476.

41. Miyachi Y, Horio T \& Imamura S (1983) Sunburn cell formation is prevented by scavenging oxygen intermediates. Clinical and Experimental Dermatology, 8: 305-310.

42. Dupuy C, Virion A, Ohayon R, Kaniewski J, Dème D \& Pommier J (1991). Mechanism of hydrogen peroxide formation catalyzed by NADPH oxidase in thyroid plasma membrane. Journal of Biological Chemistry, 266: 3739-3743.

43. Halliwell B \& Gutteridge JMC (1986). Oxygen free radicals and iron in relation to biology and medicine. Some problems and concepts. Archives of Biochemistry and Biophysics, 246: 501-514.

44. Kollias $N$ \& Baqer $A H$ (1988). The role of human melanin in providing photoprotection from solar mid-ultraviolet radiation (280-320). Journal of the Society of Cosmetic Chemists, 39: 347-354.

45. Liochev SI \& Fridovich I (1994). The role of $\mathrm{O}_{2}$ in the production of $\mathrm{OH}$ in vitro and in vivo. Free Radical Biology and Medicine, 16: 29-33.

46. Foote CS (1991). Definition of type I and type II photosensitized oxidation. Photochemistry and Photobiology, 54: 659.

47. Foote CS (1990). Chemical mechanism of photodynamic action. In: Bellingham (Editor), Future Directions and Applications in Photodynamic Therapy. SPIE Optical Engineering Press, Bellingham, WA, 115126.

48. Kochevar IE, Lambert C, Lynch M \& Tedesco AC (1996). Comparison of photosensitized plasma membrane damage caused by singlet oxygen and free radicals. Biochimica et Biophysica Acta, 1280: 223-230. 
49. Tedesco AC \& Kochevar IE (1994). Photosensitization of cell membranes: Use of dyes as sensitive probes for transmembrane electrical potential. Photochemistry and Photobiology, 50: 32S (Abstract).

50. Khan AU (1984). Discovery of enzyme generation of ${ }^{1} \mathrm{O}_{2}$ : Spectra of luminescence and IR emission. Journal of Photochemistry, 25: 327-334

51. Kanofsky JR (1984). Singlet oxygen production by lactoperoxidase: halide dependence and quantitation of yield. Journal of Photochemistry, 25: 105-113.

52. Kanofsky JR (1984). Singlet oxygen production by chloroperoxidase-hydrogen peroxide-halide systems. Journal of Biological Chemistry, 259: 5596-5600.

53. Duran N, Farias-Furtado ST, Faljoni-Alario A, Campa A, Brunet JE \& Freer J (1984). Singlet oxygen generation from the peroxidase-catalysed aerobic oxidation of an activated- $\mathrm{CH}_{2}$-substrate. Journal of Photochemistry, 25: 285-294.

54. Cadenas E \& Sies H (1984). Low-level chemiluminescence as an indicator of singlet molecular oxygen in biological systems. Methods in Enzymology, 105: 221231.

55. Cadenas E, Sies H, Nastainczyk W \& Ullrich V (1983). Singlet oxygen formation detected by low-level chemiluminescence during enzymatic reduction of prostaglandin G2 to H2. Hoppe-Seyler's Zeitschrift für Physiologische Chemie, 364: 519-528.

56. Krinsky NI (1979). Biological roles of singlet oxygen. In: Wasserman HH \& Murray RW (Editors), Singlet Oxygen. Academic Press, New York, Chapter 12.

57. Duran N (1982). Singlet oxygen in biological processes. In: Adam W \& Cilento G (Editors), Chemical and Biological Generation of Excited States. Academic Press, New York, Chapter 11

58. Ogura R \& Sugiyama M (1988). Cellular membrane damage in lipid peroxide following exposure of the skin to ultraviolet rays. In: Kligman AM \& Takase Y (Editors), Cutaneous Aging. Tokyo University Press, Tokyo, 459-471.

59. Ogura R, Sugiyama M, Sakanashi T \& Hidaka $T$ (1988). Role of oxygen in lipid peroxide of skin exposed to ultraviolet light. In: Hayaishi O, Imamura S \& Miyachi Y (Editors), The Biological Role of Reactive Oxygen Species in the Skin. Tokyo University Press, Tokyo, 55-63.
60. Lizawa O, Kato T, Tagami $\mathrm{H}$, Akamatsu $\mathrm{H}$ \& Niwa $Y$ (1994). Long-term follow-up study changes in lipid peroxide levels and the activity of superoxide dismutase, catalase and glutathione peroxidase in mouse skin after acute and chronic UV irradiation. Archives of Dermatology, 286: 4752.

61. Black HS \& Mathews-Roth MM (1991). Protective role of butyrated hydroxytoluene and certain carotenoides in photocarcinogenesis. Photochemistry and Photobiology, 53: 707-716.

62. Forman HJ \& Fisher AB (1981). Antioxidant defenses. In: Gilbert DL (Editor), Oxygen and Living Process - An Interdisciplinary Approach. Springer-Verlag, New York, 235-249.

63. Mizushima $Y$, Hoshi K, Yamagawa A \& Takana K (1991). Topical application of superoxide dismutase cream. Drugs under Experimental and Clinical Research, 17: 127-131.

64. Hamanaka $H$, Miyachi $Y$ \& Imamura S (1990). Photoprotective effect of topically applied SOD on sunburn reaction in comparison with sunscreen. Journal of Dermatology, 17: 595-598.

65. Darr D, Combs S, Dunston S, Manning T \& Pinnell S (1992). Topical vitamin C protects swine skin from ultra-violet radiation-induced damage. British Journal of Dermatology, 127: 247-253.

66. González S, Joshi PC \& Pathak MA (1994). Polypodium leucotomos extract as an antioxidant agent in the therapy of skin disorders. Journal of Investigative Dermatology, 102: 651s (Abstract).

67. Kollias N, Sayre RM, Zeise L \& Chedekel MR (1991). Photoprotection by melanin. Journal of Photochemistry and Photobiology B: Biology, 9: 135-160.

68. Natajaran $\vee$ (1995). Oxidants and signal transduction in vascular endothelium. Journal of Laboratory and Clinical Medicine, 125: 26-37.

69. DeLeo VA, Horlick $H$, Hanson D, Eisenger M \& Harber LC (1985). Ultraviolet radiation stimulates the release of arachidonic acid from mammalian cells in culture. Photochemistry and Photobiology, 41: 51-56.

70. DeLeo VA, Horlick H, Hanson D, Eisenger M \& Harber LC (1984). Ultraviolet radiation induces changes in membrane metabolism of human keratinocytes in culture. Journal of Investigative Dermatology, 83: 323-326.
71. Pentland AP \& Needleman P (1986). Modulation of keratinocyte proliferation in vitro by endogenous prostaglandin synthesis. Journal of Clinical Investigation, 77: 246-251.

72. Needleman P, Turk J, Jakschick BA Morrison AR \& Lefkowith JB (1986). Arachidonic acid metabolism. Annual Review of Biochemistry, 55: 69-102.

73. Black AK, Fircham N, Greaves MW \& Hensby CN (1980). Time course changes in levels of arachidonic acid and prostaglandins $D_{2}, E_{2}, F_{2 \alpha}$ in human skin following ultraviolet irradiation. British Journal of Clinical Pharmacology, 10: 453-457.

74. DeLeo V, Scheide S, Meshullam J, Hanson D \& Cardullo A (1988). Ultraviolet radiation alters choline phospholipid metabolism in human keratinocytes. Journal of Investigative Dermatology, 91: 303308.

75. Hanson DL \& DeLeo V (1990). Long-wave ultraviolet light induces phospholipase activation in cultured human epidermal keratinocytes. Journal of Investigative Dermatology, 95: 158-164.

76. Gamage DA, Fawzy AA \& Frason RC (1988). Preferential hydrolysis of peroxidized phospholipid by liposomal phospholipase. Biochimica et Biophysica Acta, 958: 116-124.

77. Black AK, Greaves MW, Hensby CN \& Plunner NA (1978). Increased prostaglan$\operatorname{din} E_{2}$ and $F_{2 \alpha}$ in human skin at 6 and 24 h. after ultraviolet $B$ irradiation (290$320 \mathrm{~nm})$. British Journal of Clinical Pharmacology, 5: 431-436.

78. Snyder DS \& Eaglstein WH (1974). Intradermal anti-prostaglandin agents and sunburn. Journal of Investigative Dermatology, 62: 47-50.

79. Snyder DS (1975). Cutaneous effects of topical indomethacin, an inhibitor of prostaglandin synthesis, on UV-damaged skin. Journal of Investigative Dermatology, 64: 332-335.

80. Woodward DF, Raval P, Pipkin MA \& Owen DA (1981). Re-evaluation of the effects of non-steroidal anti-inflammatory agents on UV-induced cutaneous inflammation. Agents and Actions, 11: 711-717.

81. Morrison WL, Paul BS \& Parrish JA (1977). The effects of indomethacin on long wave ultraviolet-induced delayed erythema. Journal of Investigative Dermatology, 68: 120-133.

82. Greaves MW (1986). Ultraviolet erythema: causes and consequences. Current Problems in Dermatology, 15: 18-24. 
83. Logan G \& Wilhelm DL (1966). Vascular permeability changes in inflammation. I. The role of endogenous permeability factors in ultraviolet injury. British Journal of Experimental Pathology, 47: 300-314.

84. Ikai K, Danno K, Horio T \& Narumiya S (1985). Effect of ultraviolet radiation on mast cell-deficient WMv mice. Journal of Investigative Dermatology, 85: 82-84.

85. Crunkhorn P \& Willis AL (1971). Cutaneous reactions to intradermal prostaglandins. British Journal of Pharmacology, 41: 49-56.

86. Soter NA, Lewis RA, Corey EJ \& Austen KF (1983). Local effects of synthetic leukotrienes ( $\left.\mathrm{LTC}_{4}, \mathrm{LTD}_{4}, \mathrm{LTE}_{4}, \mathrm{LTB}_{4}\right)$ in human skin. Journal of Investigative Dermatology, 80: 115-119.

87. Valtonen EJ, Janne J \& Siimes M (1964). The effect of the erythemal reaction caused by ultraviolet radiation on mast cell degranulation in the skin. Acta Dermato-Venereologica, 44: 269-272.

88. Lowenthal LJ (1963). Triprolidine hydrochloride in the prevention of some solar dermatoses. British Journal of Dermatology, 75: 254-256

89. Gupta N \& Levy L (1973). Delayed manifestation of ultraviolet reaction in the guinea pig caused by anti-inflammatory drugs. British Journal of Pharmacology, 47: 240-248.

90. Menon IA, Shirwadkar S \& Ranadive NS (1989). Nature of the oxygen species generated by xanthine oxidase involved in secretory histamine release from mast cells. Biochemistry and Cell Biology, 67: 397-403.

91. Ranadive NS \& Menon IA (1993). Reactive oxidants in photosensitized skin inflammations. In: Fuchs J \& Packer L (Editors), Oxidative Stress in Dermatology. Marcel Dekker Inc., New York, 141-168.

92. Morrison DC (1978). Receptor modulation and mast cell secretion. Journal of Investigative Dermatology, 71: 85-91.

93. Pentland AP \& Jacobs SC (1991). Bradykinin-induced prostaglandin synthesis is enhanced in keratinocytes and fibroblasts by UV injury. American Journal of Physiology, 261: R543-R547.

94. Westwick J, Li SW \& Camp SD (1989). Novel neutrophil-stimulating peptides. Immunology Today, 10: 146-147.
95. Rivas JM \& Ulrich SE (1992). Systemic suppression of delayed-type hypersensitivity by supernatants from UV-irradiated keratinocytes. An essential role for keratinocyte-derived IL-10. Journal of Immunology, 149: 3865-3871.

96. Schwarz T \& Luger TA (1989). Effect of UV irradiation on epidermal cell cytokine production. Journal of Photochemistry and Photobiology B: Biology, 4: 1-13.

97. Gallo RL, Stazewski R, Sauder DN, Knisely TL \& Granstein RD (1991). Regulation of GM-CSF and IL-3 production from the murine keratinocyte cell line PAM 212 following exposure to ultraviolet radiation. Journal of Investigative Dermatology, 97: 203-209.

98. Kondo S, Kono T, Sauder DN \& McKenzie RC (1993). IL-8 gene expression and production in human keratinocytes and their modulation by UVB. Journal of Investigative Dermatology, 101: 690-694.

99. Granstein RD (1996). Cytokines and photocarcinogenesis. Photochemistry and Photobiology, 63: 390-394.

100. Luger TA, Charon JA, Colot $M$ \& Oppenheim JJ (1983). Chemotactic properties of partially purified human epidermal cell-derived thymocyte-activating factor (ETAF) for polymorphonuclear and mononuclear cells. Journal of Immunology, 131: 816-820.

101. Pentland AP, Mahoney M, Jacobs SC \& Holtzman MJ (1990). Enhanced prostaglandin synthesis after ultraviolet injury is mediated by endogenous histamine stimulation. Journal of Clinical Investigation, 86: 566-574

102. Kupper TS, Chua AO, Flood P, McGuire J \& Gubler U (1987). Interleukin-1 gene expression in cultured human keratinocytes is augmented by ultraviolet radiation. Journal of Clinical Investigation, 80: 430-436.

103. Urbanski A, Schwarz T, Neuner PE, Krutmann J, Kirnbauer R, Kolk A \& Luger TA (1990). Ultraviolet light induces increased circulating interleukin-6 in humans. Journal of Investigative Dermatology, 94: 808-811.

104. Ansel JC, Luger TA \& Green I (1987). Fever and increased serum II-1 activity as a systemic manifestation of acute phototoxicity in New Zealand White rabbits. Journal of Investigative Dermatology, 89: 32-37.
105. Pober JS \& Costra L (1990). Cytokines and endothelial cell biology. Physiological Reviews, 70: 427-451.

106. Springer TA (1990). Adhesion receptors of the immune system. Nature, 346: 425434.

107. Osborn L, Hession C, Tizard R, Vassallo C, Luhowskyj S, Chi-Rosso G \& Lobb R (1989). Direct expression cloning of vascular cell adhesion molecule 1 (VCAM1), a cytokine-induced endothelial protein that binds to lymphocytes. Cell, 59: 12031211

108. Hession C, Osborn L \& Goff D (1990). Endothelial leukocyte adhesion molecule 1: Direct expression cloning and functional interactions. Proceedings of the National Academy of Sciences, USA, 87: 1673-1677.

109. Bevilacqua MP, Stegelin S, Gimbrone M \& Seed V (1989). Endothelial leukocyte adhesion molecule I: An inducible receptor for neutrophils related complement regulatory proteins and lectins. Science, 243: 1160-1162.

110. Norris P, Poston RN, Thomas DS, Thornhill M, Hawk J \& Haskard DO (1991). The expression of endothelial leu kocyte adhesion molecule-1 (ELAM-1), intercellular adhesion molecule-1 (ICAM1), and vascular cell adhesion molecule-1 (VCAM-1) in experimental cutaneous inflammation: a comparison of ultraviolet $B$ erythema and delayed hypersensitivity. Journal of Investigative Dermatology, 96: 763-770.

111. Barker JNWN, Allen $\mathrm{MH}$ \& MacDonald DM (1989). The effect of in vivo interferon-gamma on the distribution of LFA-1 and ICAM-1 in normal human skin. Journal of Investigative Dermatology, 93: 439-442.

112. Krutlmann J, Kock A, Schauer E, Parlow F, Moller A \& Kapp A (1990). Tumor necrosis factor beta and ultraviolet radiation are potent regulators of human keratinocyte ICAM-1 expression. Journal of Investigative Dermatology, 95: 127-131.

113. Cornelius LA, Sepp N, Li LJ, Degitz K, Swerlick RA, Lawley TJ \& Caughman SW (1994). Selective upregulation of intercellular adhesion molecule (ICAM-1) by ultraviolet $B$ in human dermal microvascular endothelial cells. Journal of Investigative Dermatology, 103: 23-28. 